[RADIOCARBON, Vol 22, No. 3, 1980, P 853-857]

\title{
SOIL DATING BY FRACTIONAL EXTRACTION \\ OF HUMIC ACID
}

\author{
KUNIHIKO KIGOSHI, NOBUKO SUZUKI, and MARI SHIRAKI \\ Gakushuin University, Tokyo, Japan
}

ABSTRACT. The addition of organic materials derived from the upper soil layer yields, for samples at greater depth, younger ${ }^{14} \mathrm{C}$ dates than the date of deposition. To find a criterion for the contamination with younger carbon in a soil sample, we examined the radiocarbon concentrations in two humic acid fractions and humin taken from the same sample. The humic acid extracted from a soil sample was divided into two fractions HAl and HA2. HA1 is the first fraction extracted by 30 minutes' heating with 2 percent $\mathrm{NaOH}$ solution, and $\mathrm{HA} 2$ is the second fraction extracted by 2 hours' heating with 2 percent $\mathrm{NaOH}$ solution after the extraction of $\mathrm{HAl}$. The residue was assumed as the humin (HM).

Many of the peat or soil samples taken from the layer just above the nonpermeable layer contain appreciable amounts of organic materials transported from the upper layer after the sedimentation of the deposits. For the limited number of cases tested here, there is a trend in which the contaminants are selectively extracted by HAl or HA2. When the soil samples are contaminated the ages of the HAl and HA2 fractions appeared to differ widely in most cases. Agreement between the HAl, HA2, and HM ages may be used as a criterion for the reliability of the soil dating.

\section{INTRODUCTION}

The addition of organic materials derived from the upper soil layer yields, for samples at greater depth, younger ${ }^{14} \mathrm{C}$ dates than the date of deposition. The elimination of secondary absorbed organic materials from the sample is difficult for peat and soil samples because the secondary absorbed materials have similar chemical properties as the originally existing organic materials.

Many workers (Olsson, 1963; Miyazaki, 1971; Tate, 1972) have investigated the radiocarbon dates of the fulvic acid, humic acid, and humin fractions of soil or peat samples. Although the fulvic acid contains more younger carbon and the humin gives the oldest age in many cases, it is hard to say which date gives a reliable estimate of the date of formation of the soil or peat layer. In order to get a reliable date of the formation of the layer, it is necessary to have additional information about the existence of modern carbon contamination in the soil or peat sample. This paper presents the result of investigations which were aimed at finding a criterion for the contamination with younger carbon in a soil or peat sample.

\section{EXPERIMENTAL METHOD}

All samples used were clayish soil samples or peat samples containing 2 to 20 percent carbon in their dry weights. We separated 2 or 3 different humic acid fractions from the samples by repeated treatments with alkaline solution. The chemical procedures for the separation of these organic fractions are shown in figure 1 . The residue left after the alkaline solution treatment was washed with hydrochloric acid and the carbon in this residue was recovered by combustion in an $\mathrm{O}_{2}$ stream and considered carbon of humin (HM) in this soil sample. In this paper, HA1, HA2, and HA3 indicate the humic acid obtained by the first, second, and third extractions, respectively. 
All carbon in HM and HA are converted to acetylene using lithium metal. The ${ }^{14} \mathrm{C}$ concentrations are measured by the usual dating procedure. The stable isotope ratios of carbon in acetylene gases are measured after the combustion of acetylene and all ages listed here are corrected for isotopic fractionation.

\section{RESULTS}

In order to examine the chemical behavior of the secondary absorbed organic materials in the alluvial deposits, we used a series of clayish peaty soil samples that were taken from a boring at Hisae, Noto Peninsula, Ishikawa Prefecture. All samples of this series have actual ages greater than 35,000 years $\mathrm{BP}$. The secondary absorbed younger organic carbon in these samples can be detected by the ${ }^{14} \mathrm{C}$ activities. The amount of young carbon contaminants in these samples are shown by the apparent ages of separated organic fractions in figure 2 with the profile of the sampling site.

A series of clayish soil samples obtained by a boring at Toriya, Noto Peninsula, $2.5 \mathrm{~km}$ from the former Hisae site, showed results similar to those in table 1. In this table the amount of recovered carbon is given as a percentage of the dry weight of the original soil sample.

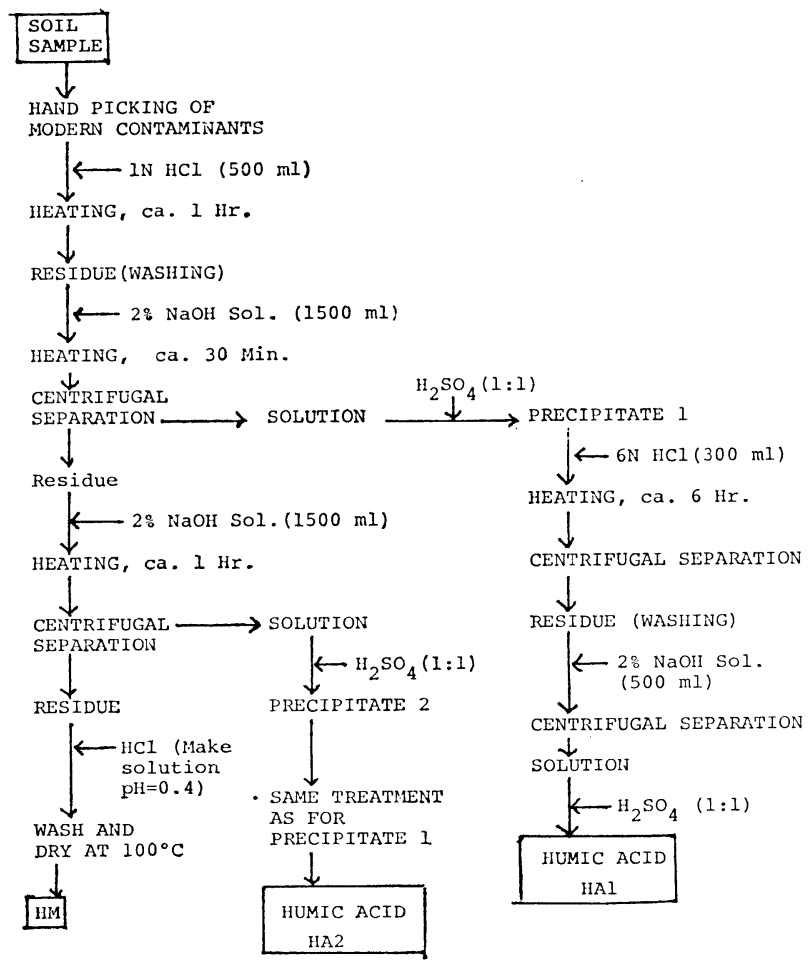

Fig 1. Chemical procedure of the separation of organic fractions (HA1, HA2, and HM) from a soil sample. The amounts of reagents given in parentheses are typical for peat samples of about $200 \mathrm{~g}$ (dry weight). 
The amount of modern carbon contaminant and its chemical behavior in these series of soil samples are characterized by the following: 1) Most of the young carbon contaminants can be extracted in the second fraction of humic acid for the samples taken from a layer above the nonpermeable layer.

2) The young carbon contaminants are mainly extracted in the first fraction of the humic acid for samples from the upper layer.

3) The peaty soil just above the nonpermeable layer contains larger amounts of young carbon contaminants than upper layer soils.

The chemical behavior of secondary absorbed young carbon extracted in these boring samples in the second humic acid fraction is seen also in some other cases (see fig 3). This behavior can be explained by a hypothesis that the young organic materials transported from the upper layers would be able to bond strongly on the fresh surface of clay minerals that has been created continuously by the weathering in the clayish soil layer. This process of absorption may occur simultaneously with the process of desorption of already absorbed contaminants. This means that the renewal of contaminants in the soil samples has been taking place in the soil layer.

The above hypothesis on the absorption and desorption processes of young organic materials agrees with the fact that even in the very old soil, the contaminating young carbon is almost modern. It is natural

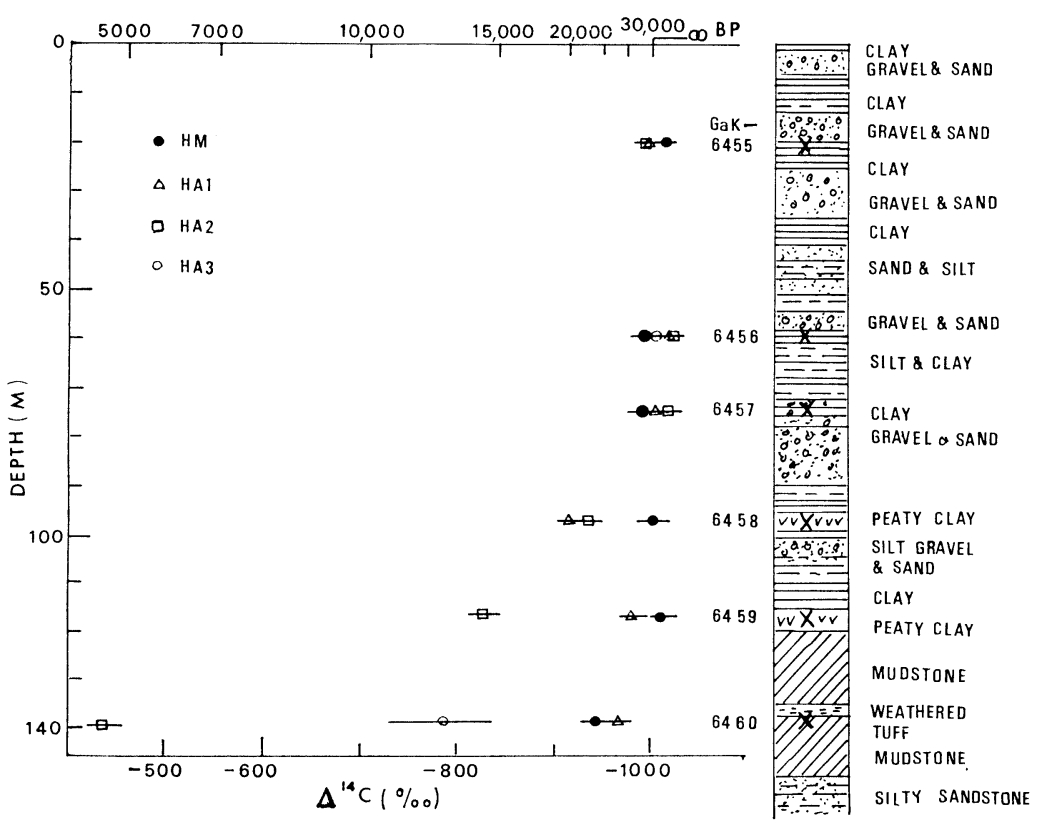

Fig $2 .{ }^{14} \mathrm{C}$ concentrations in organic fractions (HAl, HA2, HA3, and HM) separated from a series of clayish soil samples taken from Hisae, Noto Peninsula, Ishikawa Prefecture. The amounts of recovered HA1, HA2, and HM are similar to those indicated in table 1. 
TABLE 1

Apparent ages of organic fractions extracted from peaty soil from Toriya, Noto Peninsula

\begin{tabular}{lllll}
\hline Code no. & $\begin{array}{c}\text { Depth } \\
(\mathrm{m})\end{array}$ & $\begin{array}{c}\text { Organic } \\
\text { fraction }\end{array}$ & $\begin{array}{c}\text { Carbon } \\
\text { recovered } \\
(\%)\end{array}$ & $\begin{array}{c}\text { Apparent } \\
\text { age BP }\end{array}$ \\
\hline GaK-6451 & $6.0 \sim 6.1$ & HAl & 0.49 & $3170 \pm 190$ \\
& & HA2 & 0.50 & $10,310 \pm 410$ \\
GaK-6452 & $23.65-23.75$ & HM & 0.36 & $6750 \pm 890$ \\
& & HAl & 1.3 & $12,470 \pm 410$ \\
GaK-6453 & $49.1 \sim 49.2$ & HM2 & 1.8 & $>33,810$ \\
& & HA1 & 2.9 & $15,320 \pm 330$ \\
GaK-6454 & & HA2 & 1.3 & $21,160 \pm 1110$ \\
& $60.35-60.45$ & HM & 3.4 & $20,630 \pm 630$ \\
& & HAl & 0.63 & $>35,240$ \\
& & HA2 & 0.59 & $20,930 \pm 650$ \\
& & HM & 0.92 & $14,580 \pm 270$ \\
& & & & $33,130 \pm 3130$ \\
\hline
\end{tabular}

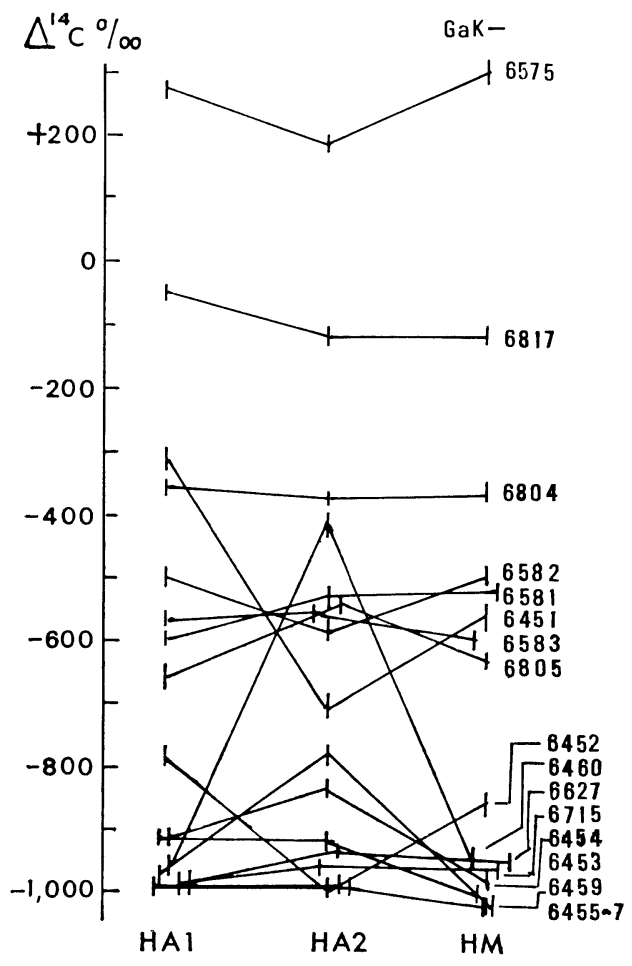

Fig $3 .{ }^{14} \mathrm{G}$ concentrations in three organic fractions (HAl, HA2, and HM) taken from peaty soil samples. 
to suppose that young age HA2 fractions in these two series of experiments consist of mainly very old (perhaps original) organic materials with a small amount of very young materials. If the contaminants would be a continuous mixture of modern to old carbon, and have an old age, the HA2 fractions would have to be composed mainly of contaminants. But it is very hard to suppose that such clear-cut separation of secondary absorbed materials is possible by a simple alkaline treatment used here.

The sample underlain by the nonpermeable layer generally contains larger amounts of contaminants than the sample taken from the waterpermeable strata. When the ${ }^{14} \mathrm{C}$ dates of a series of boring samples do not follow the stratigraphic order, a nonpermeable layer is often present just below the discordant sample.

\section{CONCLUSION}

The amount of contaminants in a soil or peat sample is appreciable when the sample is taken from above the nonpermeable layer. The presence of secondary absorbed younger materials generally results in a substantial age difference between the first and the second humic acid fractions.

The consistency of the ages obtained for the HA1, HA2, and HM organic fractions provides a criterion for the reliability of the soil ${ }^{14} \mathrm{C}$ date.

\section{ACKNOWLEDGMENTS}

The authors thank members of the Niigata Quaternary Research Group for providing the boring samples of Noto Peninsula and supplying the profiles of the boring sites.

\section{REFERENCES}

Oslon, E A, ms, 1963, The problem of sample contamination in radiocarbon datings: Thesis, Fac Pure Sci, Columbia Univ, p 105.

Miyazaki, A, 1971, Data of radiocarbon measurements in soil samples and discussion on methods of treatments (in Japanese): Quaternary Research, v 10, p 159-164.

Tate, K R, 1973, Radiocarbon datings in studies of soil organic matter-vegetation relationships, in Rafter, $\mathrm{T} A$ and Grant-Taylor, $\mathrm{T}$, eds, Internatl conf on radiocarbon dating, 8th, Proc: Wellington, Royal Soc New Zealand, v 2, p 408-420.

\section{DISCUSSION}

Haas: Between collecting HA1 and HA2 fractions, shown on your diagram to be done with two subsequent $\mathrm{NaOH}$ extractions, was there a neutralization or acidification step? If there was no such neutralization or acidification step, the distinction between $\mathrm{HA} 1$ and $\mathrm{HA} 2$ is not optimal because HA2 is going to contain some diluted HA1.

Kigoshi: There is no neutralization or acidification step between the extraction procedures of HAl and HA2. We only wash with hot water, so HA2 contains about or more than $1 / 10$ of HAl fraction. But such amount of contamination of HA1 into HA2 may not give a significant effect for our data. 